\title{
Muscle Tremor Artifact
}

National Cancer Institute

\section{Source}

National Cancer Institute. Muscle Tremor Artifact. NCI Thesaurus. Code C114148.

An electrocardiographic recording with intermittent mid to high frequency artifact in one or more leads due to muscular tremor or movement rather than cardiac activity. (CDISC) 